\title{
Ensayo
}

\section{Cultura e historia}

\author{
Uriel Bustamante Lozano \\ Licenciado en Sociales y Filosofía. \\ Docente del Departamento de Ciencias Humanas
}

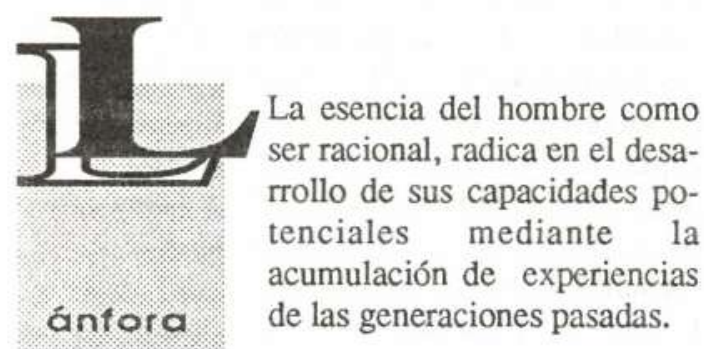

El progreso no significa ni puede significar proceso igual y simultáneo para todos. ¿Cuál es el contenido esencial del progreso atendiendo a la acción histórica?. Es el historiador quien aplica a las acciones sus hipótesis de progreso, quien interpreta sus acciones como progreso.

Sólo el futuro puede darnos la clave de la interpretación del pasado; y sólo en este sentido, nos es dado hablar de una objetividad básica en la historia. Es la explicación y justificación de la historia las que permiten que el pasado ilumine nuestra comprensión del futuro, y que el futuro arroje luz sobre el pasado.

La cultura, categoría universal de la historia

La materia de la historia se presenta al entendimiento de manera confusa, sólo al ser ordenada abriga la esperanza de tener sentido; con el orden se coordina toda la materia bajo un pensamiento que brota del entendimiento. El orden en la historia ofrece como resultado su sentido. Para que esto sea posible se recurre a dividir la historia, su segmentación se encuentra regida por categorías preestablecidas.

Al dividir la historia en eras, épocas y fases, se intenta segmentar el pasado histórico. Quien establezca fases en la historia, quien se comprometa a hacer fisuras, cortes en esta materia una y continua, lo hará según la medida que él ha adoptado, es decir, con el bisturí que él mismo ha fabricado y que puede ser exterior al proceso histórico.

Dos visiones contrarias de la historia ven en el pasado histórico la serie de hechos cuyo sentido se generaliza de un modo patente un nuevo o mejor método económico, una nueva y mejor concepción filosófica o religiosa; y, la segunda visión donde el sentido de la historia va penetrando poco a poco en el insondable abismo del olvido. Ya sea positivo ó negativo. Esta es la mirada de los observadores tanto pesimistas como optimistas. Estos conciben los acontecimientos pasados como lo causante de lo 
generativo de un continuo 'crescendo' o degenerativo un triste 'descrescendo' que termina en el presente con el grito ahogado en la garganta del sujeto contingente. El ayer es causa del estado en que vivimos hasta ahora.

Paralahistoriapráctica (arte de escribir la historia) y de una manera más amplia, habla de la historia universal: concibe la historia universal es la historiade las dinastías reinantes, de las conquistas, luchas, defensa, expansión de los grandes estados o pueblos y un gran culto a los héroes. Príncipes, caudillos, guerras y tratados de paz, modernamente alianzas y contraalianzas, he ahí lo que se indica como contenido principal de la historia y el parámetro para dividir brota por libre generación de la dinámica histórica, convirtiéndose en una empresa particular. Este es uno de los motivos por los cuales se va formando la historia de la ideas inspiración de los neohumanistas. La historia es historia de las ideas, es la sucesión y reciprocidad de las ideas históricas; las ideas nuevas significan nuevas épocas. No conciben que las ideas históricas están flotando a modo de seres misteriosos, fuera de la historia, dirigiendo las fuerzas de la misma con unos rayos invisibles. Pero las ideas no constituyen factores formativos de la historia consideradas en sí mismas, se hallan en el mundo de los conceptos y no en el de la realidad; son abstracciones y no fuerzas reales. La realidad es hechura del espíritu concreto, existente. Bajo este marco, las ideas son factores formativos de la historia. Pero las tendencias de la época, no parecen tomar una forma de idea o ideas o por lo menos no pueden expresarse como tales. Buscan instaurar categorías apriorísticas a la historia para ordenarla y captar su sentido ensalzando la importancia de algunas y relegando otras. Para ordenar la materia de la historia, se necesita una categoría más amplia cuya característica principal deba ser lo universalizante, y algunos entonces se proponen encontrarla en la cultura.

La realidad amplia que abarca por completo toda la materia de la historia, la cual espontáneamente establece también sus fases, y hasta indica su dirección, arroja luz sobre su sentido y su porvenir. Lo que brota de la dinámica de la historia es la cultura con rasgos específicos y estos se muestran en manifestaciones: en las formaciones políticas, en la economía, en el arte, en las ciencias; se diferencian de las demás ya que se encuentran enmarcadas en un contexto espacio-temporal limitado; característicaesencial que determina la sucesión de culturas, pero sujeta a una determinada «ley biológica» de nacimiento, esplendor y crisis. Encuentran en la cultura la categoría más general de la historia, un esquema, e introducen en él los hechos forzándolos. Así, por ejemplo, fijan arbitrariamente el tiempo de nacimiento y de extinción de la cultura.

Sin embargo, al igual que las anteriores miradas de la historia,ésta también, establece un parámetro al cual se le atribuye el carácter de universal, relegando a un plano secuandario los otros, olvidando puntos de vista importantes de la historia. Así, por ejemplo, a los fenómenos de descomposición, envejecimiento, decadencia, observados en la historia, nunca hemos de atribuirles el significado de un fenecer definitivo. La historia no conoce ese fenecer. La historia es el fluir inagotable de las corrientes de los hechos y acontecimientos. La forma interna de la historia es el tiempo, y éste es solamente de una dimensión lineal, es una cantidad dirigida, no tiene momentos que puedan repetirse, sustituírse unos por otros o complementarse recíprocamente. Aun cuando un fenómeno acuse a primera vista afinidad con otro de una época anterior, siendo así que es otra la dimensión espacio-temporal, necesariamente también será otro su carácter histórico. Por ésto, el contenido

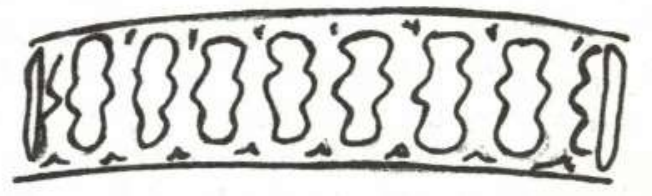


y el carácter de la historia no se agotan en el resultado o producción de culturas; ya que se encontrarían reducidos todos los hechos históricos a unas pocas culturas.

\section{Rumbos de la historia: Ranke y Droysen}

Cuál es el curso verdadero de la historia?, Cuáles son sus puntos cruciales y estaciones más importantes?, son cuestiones que en último análisis se relacionan con el sentido de la historia. $\mathrm{La}$ historia política y la de las ideas consagran su atención solamente al papel desempeñado por Estados y jefes importantes; la historia de la cultura incluye solamente los exponentes y productos históricos cuyos recuerdos se conservan por escrito o perpetúan mediante obras que perduran; a muchos pueblos, culturas y fenómenos los trata a lo más como "curiosidades» de anticuario, más no como partes orgánicas de la historia. Sin brindar así una unidad al fluír continuo de la historia. La clave que puede brindarnos ese sentido suministra consideraciones extrahistóricas; el principio y el fin son trascendentes para la historia misma. El principio de la historia según tal concepción es el hombre trascendente. La historia inmediatamente queda unida por hilos invisibles del origen común, de la naturaleza común y por consiguiente, por los de la misión y destino comunes.

Gracias a esta última mirada, Ranke ${ }^{1}$, uno de los iniciadores de la ciencia histórico alemana en el siglo XIX, penetra la visión de la historia .

Si la historia es obra de lo trascendente, aún más, si está llamada a ser de alguna manera su imitación, entonces la historia será esencialmente la vida de la comunidad humana. La comunidad ante todo, es corolario de la idea del hombre por todos los elementos y actividades de su existencia, se ve constreñido a vivir en sociedad. Comu- nidades, son las que hacen la historia, acontecimientos y resultados, conquista de una nueva patria y situaciones ecónomicas; las hazañas de la civilización y de la cultura brotan en colaboración de muchos de los que están organizados en comunidades. La comunidad es caja de resonancia, que comunica verdadera fuerza a la voz volitiva e ideológica de los individuos; la comunidad es el sujeto propiamente dicho que hace la historia; la comunidad es la corriente que presta la energía vital al curso del acontecer; y por otra parte, es la historia también la que hace las comunidades. En toda la corriente de la vida de la comunidad, se entretejen todas las obras y todos los quereres de las generaciones pasadas y futuras; la comunidad es un tejido fabricado no solamente por la generación presente, sino también, por todas las generaciones del pasado y del porvenir. Es decir, la historia está llamadaa hacer madurar y resolver también aquellos grandes problemas que van envueltos en la gran idea de la comunidad.

En la concepción histórica del mundo de Ranke, la verdad del dogma teológico no puede hallar una satisfactoria explicación arrojándolo a los parámetros de la razón, ni mucho menos utilizandoconceptos que la filosofía nos proporciona; la historia universal al buscar sustento en la teología, no sólo se muestra como un sistema acabado de principio a fin, gracias a la participación en ésta de los designios de la voluntad que rige tal historia, además, de ser creadora de estos designios que conformarían el contenido de la historia universal. No se convierte la historia universal en un sistema apriorístico, al contrario, el sujeto del acontecer es consciente de ese acontecer histórico, donde el sujeto no ve restringida su libertad de acción. Para Ranke la libertad de acción constituye los elementos constructivos del nexo histórico, son las escenas de libertad las que determinan el nexo. Por lo tanto, en ese tejido infinito de sucesos, existen unos que resaltan de los demás por la traza de no concentrar decisiones 
históricas. Ya que sólo hay decisión, cuando se actúa libremente; los momentos históricos están caracterizados verdaderamente por la toma de una decisión sobre algo, ya que su efecto manifiesta un significado pleno y verdadero y son estas decisiones históricas, las que confieren su articulación al nexo histórico. Gracias a este nexo, en el discurrir histórico, los acontecimientos se condicionan los unos a los otros, pero nada está en virtud de los demás, formando por lo tanto, períodos medibles de tiempo. Es así como una acción libre en la toma de una decisión se vuelve histórica y son momentos de auge o crisis. Los sujetos que han obrado libremente son denominados por Ranke espíritus originales. Pero a esta concepción de libertad, se añade el de fuerza, categoría central de la concepción histórica del mundo. Junto a la libertad está la necesidad, ya que la historia no es productora de momentos de manera mecánica o de modo determinista. El objeto de la historiografía no es otro que el de olfatear a ras de piso las huellas de la libertad en el discurrir de los acontecimientos, y es así como la historia adquiere coherencia interna.

Otras fuerzas vivas la constituyen los estados individuales, «seres espirituales reales», «ideas de Dios» no como imposición de alguna voluntad o plan trazado. Es gracias al uso de la categoría de fuerza como se nos permite pensar esa relación o dependencia de los momentos de la historia, como dato fundamental y primero, pero también esta categoría sólo es realmente como juego de fuerzas; la historia también es un juego de fuerzas que procede con continuidad. Para Ranke la historia es así: "suma en curso», pretendiendo ubicarse en el mundo de la experiencia dando al traste con la concepción apriorística de la historia del mundo.

Con «suma en curso» se concibe a la historia como un todo, aunque ésta no se halle terminada. La sumatoria de cantidades heterogéneas implica la reunión en una unidad bajo la cual, se agrupan por un sentido impuesto como anterior a toda suma. Por ejemplo: Heródoto, al desaparecer el papel de la divinidad griega hace aparecer con claridad dos ideas: el papel decisivo del hombre en la historia, y, la existencia de fuerzas mecánicas que se establecen por encima de los dioses y los hombres. Nadie escapa a la fatalidad del Hado, pero eso no constituye ninguna fuerza consciente, sino una fuerza ciega a la que el hombre astuto y prudente puede escapar. Este es el supremo sentido de libertad, el hombre no es producto histórico, se considera como un fenómeno moral que presenta ejemplos y no unidad.

\section{Curso de la historia y la cultura}

En conclusión, ninguna opinión previa sobre el sentido de la historia debe premeditar la investigación misma. Otro presupuesto que determina su contenido, es que la idea de unidad implica continuidad ininterumpida de la historia universal. Continuidad no me remite a un contenido en concreto (sólo son sucesos que se vienen a sumar). Apriori a la investigación, no se pueden introducir cosas que están sobrepuestas como escamas o tejas que invitan a la profundización de los nexos históricos.

La diferencia entre occidente y oriente, que establece Ranke, es la continuidad histórica que constituye la forma de existencia de la cultura. La unidad histórica del mundo reposa sobre la unidad de la cultura occidental a la cual pertenecen la ciencia en general y la historia en particular. Para Ranke la constancia del desarrollo de la historia está fundamentada en la conciencia que es la que convierte la historia en historia.

La realidad del mundo de la historia consiste en una configuración y concepción que el espíritu debe rendir siempre a lo nuevo de las finitudes siempre cambiantes a las que pertenece todo el 
que actúa. Lo que Droysen ${ }^{2}$ investiga es la significación en el movimiento histórico de los poderes morales, los cuales fundan el modo de ser de la historia, como su posibilidad de crecimiento. La fuerza moral del individuo se convierte en un poder histórico en la medida en que participa en el trabajo para los grandes objetivos comunes. La moral es la que permanece todopoderosa en el curso de las cosas. La fuerza sólo existe a través del mundo moral como mediador para llegar a concebirse como una realidad histórica. Todos participan de ese mundo moral de diversas maneras. El movimiento continuado del mundo moral, que es un mundo de libertad, presenta a las grandes personalidades como un momento en ese movimiento. El apriorismo histórico está en que sólo en nuestras manos está el conocer el objetivo, la orientación de este movimiento. A éstos objetivos se dirige el trabajo de la humanidad histórica; sólo pueden ser objeto de nuestra intuición y fe. La fórmula de Droysen consiste en que para lograr un conocimiento histórico, se debe recurrir a comprenderlo investigándolo. Sólo investigando "sin descanso la tradición, descifrando siempre nuevas fuentes y reinterpretándolas sin cesar, se va acercando poco a poco la investigación a la idea. Como conocimiento histórico, delimita el que-hacer del historiador frente a la realidad total con el arte y frente a la comunión íntima con las almas, ya que suprocedimiento es el de las ciencias naturales». La investigación es asumida como «el viajero científico» que se arriesga a lugares desconocidos abarcando el conocimiento de la naturaleza y el mundo histórico. Los poderes morales son fundamentales para el historiador ya que éste encuentra en aquellos su verdad; tras la investigación incesante de la tradición se logra al final siempre comprender; y éste estriba en la forma. Comprender vincula al yo con las comunidades morales, las cuales son comprensibles porque son expresión y ésta eleva la realidad histórica a la esfera de lo que tiene sentido.

Cada pueblo y cada cultura de una manera u otra, llevan en su presente todo su pasado. Al empalmarse realmente con la corriente de la historia universal, todo cuanto estaba acumulándose y madurando en el silencio de la historia, entró en la esfera de la luz; de un modo análogo en el curso de la historia concreta cada pueblo y cada acontecimiento se empalma con la corriente de vida de la historia. Hay puntos cruciales de la historia que se empalman siempre con importantes acontecimientos históricos; la historia no es solamente contenido, sino también marco y cauce; no solamente cultura, sino también acontecer.

Fueron los judíos y los cristianos tras ellos, los que introdujeron un elemento del todo nuevo, postulando una meta hacia la que se dirige el proceso histórico; la noción teleológica de la historia. De esta forma adquirió la historia sentido y propósito, pero a expensas de su carácter secular. El alcance de la meta de la historia, implicaría automáticamente el final de la historia. El renacimiento reestableció la concepción clásica de un mundo antropocéntrico y de la primacía de la razón, pero sustituyó la pesimista visión clásica del futuro por una visión optimista derivada de la tradición judeo-cristiana. Los racionalistas de la ilustración, que fueron los fundadores de la moderna historiografía, conservaron la visión teleológica judeo-cristiana, pero secularizaron la meta; pudieron así reestablecer el carácter racional del propio proceso histórico. La historia se convirtió en el progreso haciala consecución de laperfección terrenal de la condición humana.

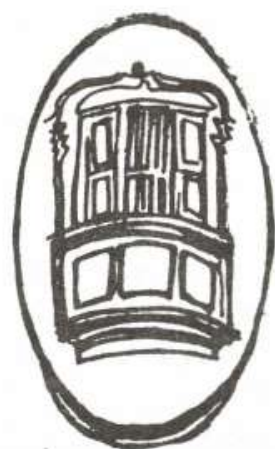

${ }^{1}$ H. G. GADAMER, Verdad y Método, Salamanca, Sígueme 1977, capítulos 2 y 3 .

2 Ibidem 